\title{
Spatial Pattern in Solid Minerals Distribution in Cross River State, Nigeria
}

\author{
NJAR, GN \\ Department of Geography \& Environmental Science, University of Calabar \\ *Correspondence Author Email: harjogold01@yahoo.com
}

\begin{abstract}
The study examined the extent of solid mineral distribution in Cross River State using Geographic Information System (GIS), base map and Global Positioning System (GPS) for data collection; Z-score variate and Nearest Neighbour Analysis (NNA) for data analysis. The result of NNA indicated that solid mineral in Cross River State depicted a clustering pattern with apparent clustering observed in the Central Senatorial District of the state. Spatial pattern of mineral distribution revealed that Obubra and Ikom had highly abundant of mineral resources followed by Akamkpa; Yala, Biase, Obanliku and Boki were moderately abundant. Yakurr, Abi, Etung, Ogoja, Calabar South, Calabar Municipality, Bakassi and Akpabuyo were less abundant. The study suggested that effective mapping of solid minerals in Cross River State would facilitate exploration activity in the respective communities and put the communities in the international stage for proper utilization of available mineral deposits by multinationals.
\end{abstract}

\section{DOI: https://dx.doi.org/10.4314/jasem.v22i10.23}

Copyright: Copyright $(0) 2018$ Njar. This is an open access article distributed under the Creative Commons Attribution License (CCL), which permits unrestricted use, distribution, and reproduction in any medium, provided the original work is properly cited.

Dates: Received: 05 September 2018; Revised: 27 October 2018; Accepted 30 October 2018

Keywords: Solid mineral distribution, Mapping, Spatial pattern

Cross River State is endowed with a variety of minerals in addition to abundant oil and gas reserves that have been driving the state's economy in the past decades (RMRDC, 2005 cited in Njar, 2017). However, the inability of government or investors to undertake adequate inventory or development efforts that are sustainable is rooted in poor quality data collection, organization and management practices which cannot serve as a basis for any meaningful plan of action. Similarly, the Organization of African Unity (OAU), now AU in its Lagos Plan of Action for Economic Development of Africa (2002) observed that the major problems confronting Africa include lack of information on natural resources endowment and lack of adequate capacity (capital, skill and technology) for the development of resources. The potentials of most of the minerals have not been optimally exploited due to insufficient information such as maps and charts about their distribution and location (Njar, 2017). In order to tap the inherent economic benefits of these abundant resources, there is need to establish a database that will enhance and optimize their exploration and exploitation with the aim of deriving maximum benefits from such venture. The importance of minerals mapping has attracted the attention of scholars from diverse fields of human endeavour in the past, with the sole aim of enhancing their exploration, exploitation and utilization for the entire benefit of the society. Due to its importance, there is sizeable literature on the usefulness of GIS and remote sensing in the mapping of minerals across regional and national levels (Asadi et al., 2007; Mbile et al., 2009; Oyono et al., 2010). Other studies like those of Kankara (2002), Amoka and Jatau (2010) and Kankara (2013) among several other only provided holistic information of mineral resources that is not location specific and essentially show the importance of GIS and remote sensing devices in the monitoring of minerals without mapping and showing their distributional pattern. For instance, Kankara, (2013) examined how remote sensing techniques can be used to monitor natural resources in Kaduna and Katsina States of Nigeria. The study looked at how digital image processing can be used to explore and delineate mineral deposits, but the study did not map the distribution of minerals in the two States. Other studies done in Nigeria using modern remote sensing applications include that of Ananaba and Ajakaiye (1987) that showed evidence of tectonic control of mineralization in Nigeria from lineament density analysis and Goki et al., (2005) that used digitally processed Landsat 5 imageries to map mineralized pegmatites around Nasarawa State. Other studies that focused on hydrogeological applications included those of Odeyemi et al., (1999) and Ayok (2009). However, these studies only showed how GIS and remote sensing devices could be used to monitor and possibly map minerals. They basically provide descriptive information on solid minerals without mapping and showing their distributional pattern as 
well as areas of abundance for easy identification. They did not delineate areas of surplus and deficit in minerals distribution. The mapping of minerals and showing their distributional pattern in spatial scale or geographical units will help in the marketing of the resources to both local and foreign investors. It is on this background that the present study was carried out to critically examine spatial pattern in solid minerals distribution in Cross River State, Nigeria.

\section{MATERIALS AND METHODS}

Study area: Cross River State, Nigeria lies between latitudes $5^{\circ} 32^{\prime}$ and $4^{\circ} 27^{\prime}$ north of the equator, and longitudes $7^{\circ} 50^{\prime}$ and $9^{\circ} 28^{\prime}$ east of the Greenwich Meridian. Cross River State covers a land mass of approximately 23,074 square kilometers. Cross River State land mass is made up of Basement Complex rocks and the Sedimentary Basins (Ekwueme, 1987). The state has tropical-humid climate with wet and dry seasons. Average temperatures range between $15^{\circ} \mathrm{C}$ $30^{\circ} \mathrm{C}$, and the annual rainfall between $1300-$ $3000 \mathrm{~mm}$, (Ita, 2011). Cross River State, is home to one of the last remaining contiguous forest stands in West Africa. The forest ecosystem stabilizes local weather patterns and provides water in this region of Nigeria. The vegetation zones of Cross River State falls within the mangrove swamp forest in the south, stretching through the deciduous and savanna regions in the north. The state is blessed with numerous solid minerals.

Sampling technique and data collection: The stratified sampling technique was employed in the categorization and classification of the various solid minerals in the 18 Local Government Areas of the State. Different methods were employed to collect data for the study. Basically, the use of GIS, base map and Global Positioning System (GPS) constituted the data collection methods. Global Positioning System (GPS) was used to determine the location of solid minerals.

Data calibration: In order to characterize and quantify solid minerals in the study area as well as show their distributional patterns, local government areas in Cross River State where a particular solid mineral exists is assigned the value ' 1 ' and if such solid mineral does not occur or exist in the area, the value ' 0 ' is assigned. Hence, the value ' 1 ' stands for presence of a particular solid mineral while ' 0 ' represent absence of the said mineral. The assigning of values enabled characterization and quantification to be carried out using Z-score variate which is defined below:

$$
Z=\frac{x-\mu}{\sigma}
$$

Where $Z=$ Standard (normal) or $Z$ score $X=$ member element of group; $\mu=$ mean of expectation; $\sigma=$ standard deviation

Techniques of data analysis: The data obtained from the field were analyzed using tables, charts, maps and nearest Neighbour analysis (NNA). NNA was used to ascertain the distribution pattern of solid minerals in Cross River State. Nearest Neighbour Analysis (NNA) produces a figure usually expressed as $\mathrm{Rn}$ which measures the extent to which a particular pattern is either clustered (nucleated), random or regular (uniform). Clustering occurs when all the dots are very close to the same point $(R n=0)$; random distributions occur where there is no pattern at all ( $R n$ equals 1.0). The usual pattern for settlement is random with a tendency for clustering or regularity. Regular patterns are perfectly uniform. They have an $R n$ value of 2.15 which means that each place is equidistant. The formula of NNA is given below:

$$
R_{n}=\frac{D(o b s)}{0.5 \sqrt{\frac{a}{n}}}
$$

Where; $\mathrm{Rn}=$ nearest neighbour value; $\mathrm{D}(\mathrm{Obs})=$ mean observed nth distance; $\mathrm{a}=$ area under study; $\mathrm{n}$ $=$ total number of points

The analysis requires the determination of observed distance with expected distance in conjunction with the area of study in projected data format. The analysis was done using ArcGIS 9.1 software. In order to determine the spatial pattern in mineral distribution among the geographic units or Local Government Areas in Cross River State as well as ascertain areas of high abundance to less abundance, the standard scores additive model was used. For this method, the raw data was weighted by the number of variable for each frequency (presence of minerals) of solid minerals. Under this method, the score of minerals ' I' in each geographic unit variable ' $\mathrm{j}$ ' is standardized into $\mathrm{Z}$ score relative to the scores of other minerals by transforming all the scores to zero mean and unit standard deviation on the variable ' $\mathrm{j}$ '. The Z-score variate has been used extensively used by different scholars to analyze the spatial variation in the distribution of geographic attributes and to determine pattern of distribution (Parry et al., 2012; Korter and Ipinyomi, 2016; Antwi et al., 2016).

\section{RESULTS AND DISCUSSION}

Solid minerals reference map of Cross River State: Figure 1 gives an X-ray of solid mineral reference map of Cross River State. It shows the various types of solid minerals and their respective locations in the state. The map provides a fast way of understanding 
the distributional pattern of solid minerals across the various geographic units. From Figure 1, the Local Government Area with high level of occurrence and distribution of solid minerals are easily identified. For instance, a cursory look at the figure shows apparently that Ikom Local Government Area is most endowed with solid minerals due to the presence of various mineral deposits in the area.

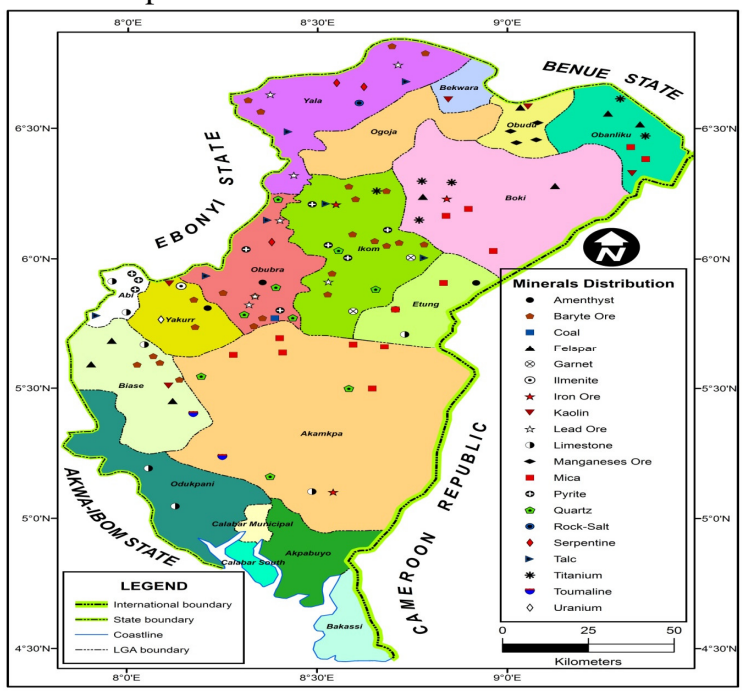

Fig 1: Reference map of solid mineral

Distributional pattern of solid minerals in Cross River State: The result with NAA ratio of 0.91803 is presented in Figure 2. The Figure 2 clearly shows that the pattern exhibits a cluster pattern $(R n=<1)$. A further analysis to test the degree of randomness as shown by the NNA value was established with the $\mathrm{z}$ score statistics ( $\mathrm{z}$-score $=-1.6962 .2)$ at 0.10 significant level which was found to be significant. Z-scores are simply standard deviations, while the p-value is a numerical approximation of the area under the curve for a known distribution, limited by the test statistic. The p-value is a probability. For the pattern analysis tools, it is the probability that the observed spatial pattern was created by some random process. When the p-value is very small, it means it is very unlikely (small probability) that the observed spatial pattern is the result of random processes, so you can reject the null hypothesis. Thus, the result of the analysis showed a clustering pattern but also revealed that the clustering pattern was tending more to random distribution than cluster pattern. Thus, the pattern of distribution $\mathrm{x}$-rayed by Figure 3 verifies the clustering pattern of solid minerals in Cross River State. The clustering pattern is more obvious in the Central Senatorial District of the state.

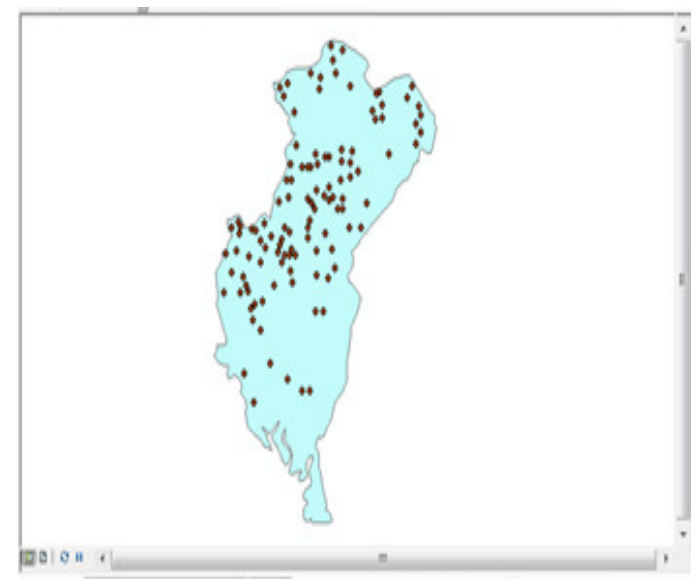

Fig 2: Result of Nearest Neighbour Analysis

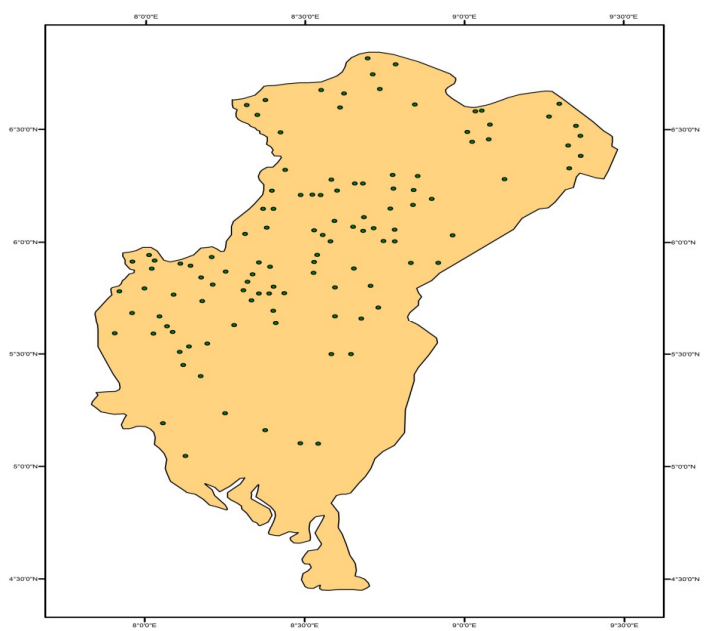

Fig 3: Distributional pattern of solid minerals in Cross River State

Relative distribution of solid minerals in Cross River State: Figure 4 gives vital information on the relative distribution of solid minerals in Cross River State. It indicated that 20 per cent of the solid mineral deposits in Cross River State were found in Obubra (they included barite ore, manganese ore, felspar, quartz, amenthyst, lead ore, pyrite, rock salt, talc and coal), 19 per cent was found in Ikom (which included barite ore, quartz, garnet, lead ore, iron ore, pyrite, talc and titanium), 12 per cent in Akamkpa (manganese ore, mica, quartz, iron ore, limestone and tourmaline), 10 and 8 per cent of the solid mineral deposits were in Yala (barite ore, lead ore, rock salt, serpentine and talc) and Biase (barite ore, feldspar, kaolin, limestone and tourmaline) LGAs respectively. This therefore implies that 69 per cent of the solid mineral deposits are found in Obubra, Ikom, Akamkpa, Yala and Biase LGAs. Surprisingly, Calabar South, Bakassi, Akpabuyo, Calabar Municipality and Ogoja have 0 per cent of solid minerals, which invariably implies these LGAs do not have solid minerals deposits. 


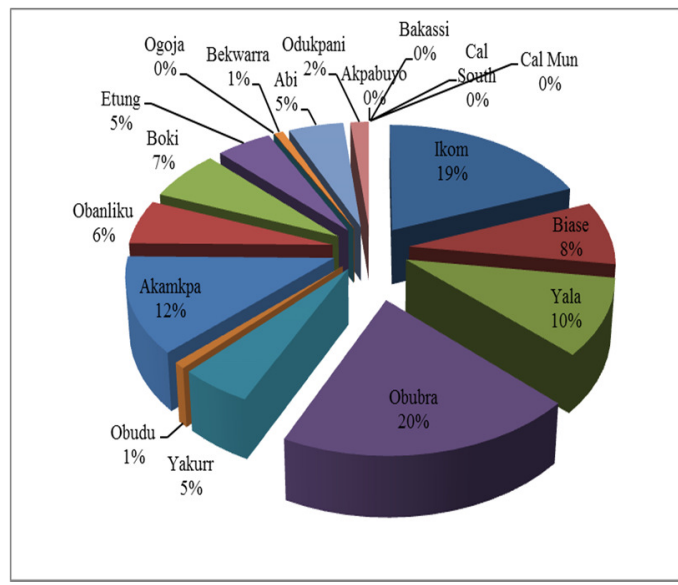

Fig 4: Distribution of solid minerals in Cross River State

Spatial pattern of solid mineral distribution: Weighted raw values of the respective solid minerals were summed up and transformed into standard scores. The transformation gives scores that form the matrix represented in Table 1. A cursory look at the signs of the standard deviates (Z-scores) shows that only two (2) LGAs are found to be highly blessed with solid minerals, one LGA has abundant solid minerals, four (4) LGAs have moderately abundant minerals, while eleven (11) LGAs are less abundant with regard to the distribution and occurrence of solid minerals.

Table 1: Standard deviates/scores of solid mineral distribution

\begin{tabular}{llll}
\hline LGAs & $\begin{array}{l}\text { Solid } \\
\text { mineral }\end{array}$ & $\begin{array}{l}\mathbf{X}- \\
\text { Mean }\end{array}$ & $\begin{array}{l}\text { X- } \\
\text { Mean/ }\end{array}$ \\
\hline Ikom & 23 & 16.28 & 2.14 \\
Biase & 10 & 3.28 & 0.43 \\
Yala & 12 & 5.28 & 0.69 \\
Obubra & 24 & 17.28 & 2.27 \\
Yakurr & 6 & -0.72 & -0.09 \\
Obudu & 1 & -5.72 & -0.75 \\
Akamkpa & 15 & 8.28 & 1.09 \\
Obanliku & 7 & 0.28 & 0.04 \\
Boki & 8 & 1.28 & 0.17 \\
Etung & 6 & -0.72 & -0.09 \\
Ogoja & 0 & -6.72 & -0.88 \\
Bekwarra & 1 & -5.72 & -0.75 \\
Abi & 6 & -0.72 & -0.09 \\
Odukpani & 2 & -4.72 & -0.62 \\
Akpabuyo & 0 & -6.72 & -0.88 \\
Bakassi & 0 & -6.72 & -0.88 \\
Cal South & 0 & -6.72 & -0.88 \\
Cal Mun & 0 & -6.72 & -0.88 \\
\hline \multicolumn{3}{c}{ Total } & \multicolumn{3}{c}{0.04} \\
\hline Where X = Respective LGAs; Mean $=6.72 ; \delta=7.62$ \\
\multicolumn{5}{c}{}
\end{tabular}

The highly abundant LGAs are Obubra and Ikom. It is important to note the primacy of Obubra and Ikom LGAs, as they have the highest standard positive deviate of +2.27 and +2.14 respectively accounting for thrice as much as the scores of some LGAs in the moderately abundant group put together. Akamkpa is the only LGA within the abundant category, while
Yala, Biase, Obanliku and Boki fall in the moderately abundant group. The scores of the eleven (11) less abundant LGAs ranged from -0.09 for Yakurr, Abi and Etung respectively to -0.88 for Ogoja, Calabar South, Calabar Municipality, Bakassi and Akpabuyo. The information depicted in Table 1 reveals that the extent of spatial inequality in the distribution of solid minerals. This calls for concerted effort from the government to develop areas with highly to abundant solid minerals for the overall good of the state.

In addition, the information displayed in Figure 5 shows varying pattern of inequality in the distribution of solid minerals in Cross River State. The figure clearly shows privileged and underprivileged as well as most privileged LGAs. It also shows LGAs that are most privileged such as Obubra, Ikom and Akamkpa. The privileged LGAs are Biase, Yala, Boki, and Obanliku. Among the underprivileged LGAs, Calabar South, Calabar Municipality, Ogoja, Bakassi and Akapbuyo constitute the most underprivileged LGAs in Cross River State in the distribution and abundance of solid minerals, these LGAs have to signs of solid mineral deposits and the less privileged LGAs are Yakurr, Etung and Abi.

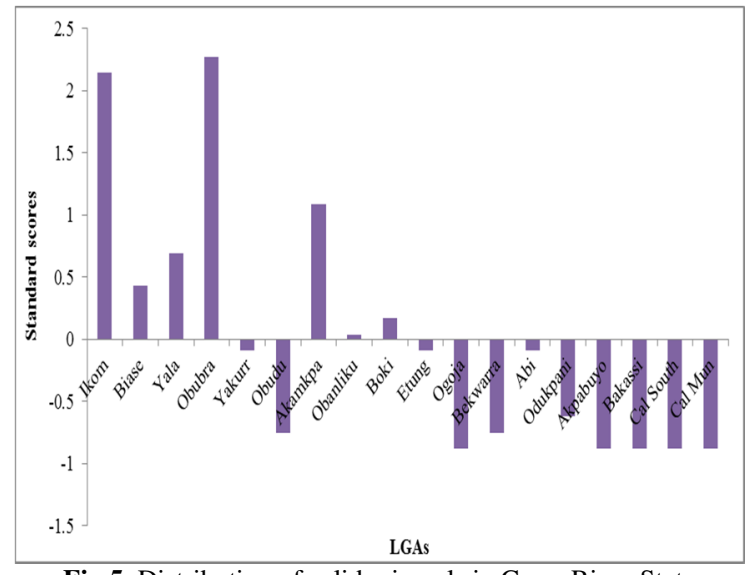

Fig 5: Distribution of solid minerals in Cross River State

Spatial pattern of solid mineral distribution across senatorial zones: Information on the spatial pattern in the distribution of solid mineral resources among the three senatorial zones of Cross River State is shown in Table 2. A cursory look at the signs of the composite deviates reveals that the central senatorial zone (4.14) is most privileged in the distribution and abundance of solid minerals, while the northern (-1.47) and southern $(-2.62)$ senatorial zones are under-privileged and most under-privileged respectively. This further means that the most privileged senatorial zone is central Cross River comprising of five (5) local government areas, while the southern senatorial zone was the most 
underprivileged in the distribution of solid mineral comprising of seven (7) local government areas.

Table 2: Z- scores of solid mineral distribution among senatorial

\begin{tabular}{lc}
\multicolumn{2}{c}{ zones } \\
\hline Senatorial Zones & Composite scores \\
\hline Northern zone & -1.47 \\
Central zone & 4.14 \\
Southern zone & -2.62 \\
\hline
\end{tabular}

Furthermore, the information presented in Table 2 is further explained with Figure 6. The figure shows most privileged and most deprived senatorial zones in regards to the natural endowment of solid minerals. As noted above, the most advantageous/privileged zone is the central senatorial. On the deprived zone categories, northern senatorial and southern senatorial zones are less underprivileged and most underprivileged respectively. This shows that the southern senatorial zone with the highest local government and administrative blocks is poorly endowed with solid minerals, while the central senatorial zone with the lowest number of local government areas is richly blessed. The figure shows a discernible pattern of inequality in the natural endowment of solid mineral resources across the state.

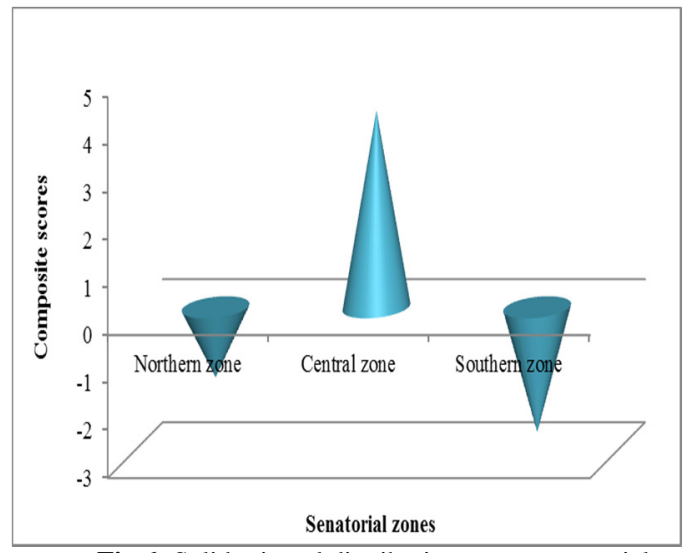

Fig 6: Solid mineral distribution across senatorial zones

Relative distribution of solid minerals across senatorial zones: The distribution and relative abundance of solid mineral resources across the three senatorial zones in Cross River State is shown in Figure 7. The information indicates that majority (54\%) of the solid mineral deposits are found in the central senatorial zone, this is followed by the northern zone with $24 \%$ and lastly the southern senatorial zone with $22 \%$. The bulk of the solid mineral deposits namely barite ore, manganese ore, felspar, mica, quartz, garnet, amenthyst, lead ore, kaolin, iron ore, pyrite, limestone, uranium, illmenite, rock salt, talc and coal are found in the central senatorial zone at varying quantities. In the northern senatorial zones, the following solid minerals are found barite, felspar, mica, lead ore, kaolin, iron ore, rock salt, serpentine, talc and titanium, while in the southern senatorial zones, manganese ore, feldspar, mica, quartz, kaolin, iron ore, limestone and tourmaline occur in varying quantities. Further analysis shows that of the 20 catalogued solid minerals, 18 with the exception of serpentme and tourmaline are found in the central senatorial district, in the northern zone, only 10 out of the 20 solid minerals are found. For the southern zone, out of the 20 catalogued solid minerals, 8 are found within its territorial boundaries. This therefore means that the three senatorial zones are richly endowed with varying quantities of solid minerals, and surprisingly, majority of these solid minerals remain latent and unexploited for the overall benefits of indigenes of Cross River State and beyond.

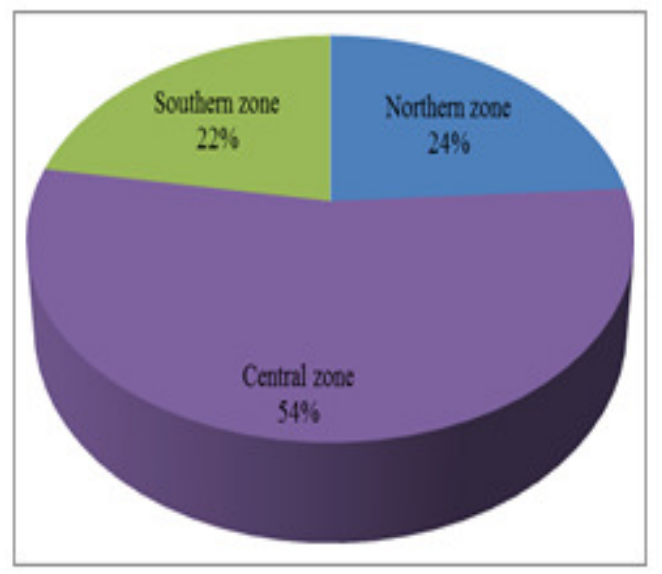

Fig 7: Distribution of solid minerals across senatorial zones

Conclusion: The study has shown that Cross River State is richly endowed with 20 solid minerals distributed unequally among the 18 geographic units. These solid minerals if adequately mapped and marketed will provide increased revenue to the government as well as facilitate rural development The composite scores of the distribution of solid minerals show that the Central Senatorial Zone with the lowest number of local government areas is richly blessed with abundant solid minerals. Barite Ore, Mica, Quartz, Felspar and Pyrite with relative abundance and distribution across the state should be marketed to the outside world. This is feasible through government's good political will in economic development.

\section{REFERENCES}

Amoka, IS; Jatau, SB (2010). Application of Geographic Information System for mineral exploration in Nigeria. Proceedings of the 
International Conference on Software Engineering and Intelligent Systems, 1, 361-370.

Ananaba, SE; Ajakaiye, DE (1987). Evidence of tectonic control of mineralization in Nigeria from lineament density analyses. Intl. Journal of Remote Sensing, 8 (10): 1445-1453.

Antwi, M; Duker, AA; Fosu, M; Abaidoo, RC (2016). Geospatial approach to study the spatial distribution of major soil nutrients in the Northern region of Ghana. Cogent Geoscience, 2: $1-13$.

Asadi, SS; Vuppala, P; Reddy, MA (2007). Remote sensing and GIS techniques for evaluation of groundwater quality in Municipal Corporation of Hyderabad (Zone-V), India. Int. J. Environ. Res. Public Health, 4(1), 45-52.

Ekwueme, BN (1987). Structural orientations and precambrian deformational episodes of Uwet Area, Oban Massif, SE Nigeria. Precamb. Res., 34: 269-289.

Elsayed, ZKA (2010). Sudan experience in using remote sensing for mineral prospecting. Available at: https://www.researchgate.net/profile/Khalid_El sayed_Zeinelabdein/publication/231633111_Su dan_experience_in_using_remote_sensing_for mineral_prospecting/links/0912f507283a2a188f 000000/Sudan-experience-in-using-remotesensing-for-mineralprospecting.pdf?origin $=$ publication_detail

Goki, NG; Oha, IA; Ike, EC; Bala, EA (2005). The use of digitally processed Landsat 5 T TM imagery to map mineralized pegmatites around Nassarawa, central Nigeria. First international Workshop on Geodesy and Geodynamics in Toro, Bauchi State.

Ita, AE (2011). Variation in regional socio-economic development in Cross River State. Unpublished Ph.D. Dissertation, University of Calabar, Cross River State, Nigeria

Johnson, CP; Deshmukh, B; Kale, M (2007). Role of GIS and remote sensing in the sustainable development of Mauritius. Available at: http://creativecommons.org/licenses/by/3.0/us/

Kankara, AI (2013). Monitoring natural resources using remote sensing techniques: current situation in Kaduna and Katsina States Nigeria.
Advance in Electronic and Electric Engineering, 3 (1): 31-40.

Kankara, AI (2013). Monitoring natural resources using remote sensing techniques: current situation in Kaduna and Katsina States Nigeria. Advance in Electronic and Electric Engineering, 3 (1): 31-40.

Kankara, IA (2002). Solid minerals development in Katsina State: constraints and prospects. An unpublished M.Sc. Thesis, Geography Department, Bayero University Kano.

Korter, GO; Ipinyomi, RA (2016). Spatial dependence in agricultural employment. Agrosearch, 16 (1): $11-12$.

Mbile, P; Ndzomo-Abanda, G; Essoumba, H; Misouma, A (2009). Alternate tenure and enterprise models in cameroon: community forests in the context of community rights and forest landscapes. World Agroforestry Centre and Rights and Resources Initiative (RRI): Washington, D.C., page 2.

Njar, GN (2017). Mapping of mineral distribution in Cross River State, Nigeria. Unpublished PhD Thesis, University of Calabar, Nigeria

Odeyemi, IB; Anifowose, YB; Asiwaju YA (1999). Multi-technique graphical analysis of fractures from remote sensing $i$ images of basement regions of Nigeria. Journal of Mining and Geology, 35(1): $9-21$.

Oyono, R; Mbile, P; France, M; Bandiaky, S (2010). Mapping communities, mapping rights: participatory community mapping as rights contestation in Cameroon. Policy Matters, 17: $156-162$.

Parry, JA; Ganaie, SA; Nengroo, ZA; Bhat, MS (2012). Spatial analysis on the provision of urban amenities and their deficiencies - a case study of Srinagar City, Jammu and Kashmir, India. Research on Humanities and Social Sciences, 2 (6): $192-219$. 